\title{
Correction to: An unusual tracheal foreign body in a middle-aged male with a 15-year history of coal use: a case report
}

Li-juan Zhong ${ }^{1,2}$, Min Yan², Yi Wang ${ }^{2}$, Dai-quan Zhou², Jian-ming Tang ${ }^{3}$ and Shou-hong Xiang ${ }^{2 *}$

\section{Correction to: BMC Med Imaging (2021) 21:35 https://doi.org/10.1186/s12880-021-00561-z}

Following the publication of the original article [1] the authors informed us that an incorrect image had unfortunately been included as Fig. 1 in their article.

The correct Fig. 1 is shown here below and has now been updated in the original article. 
a

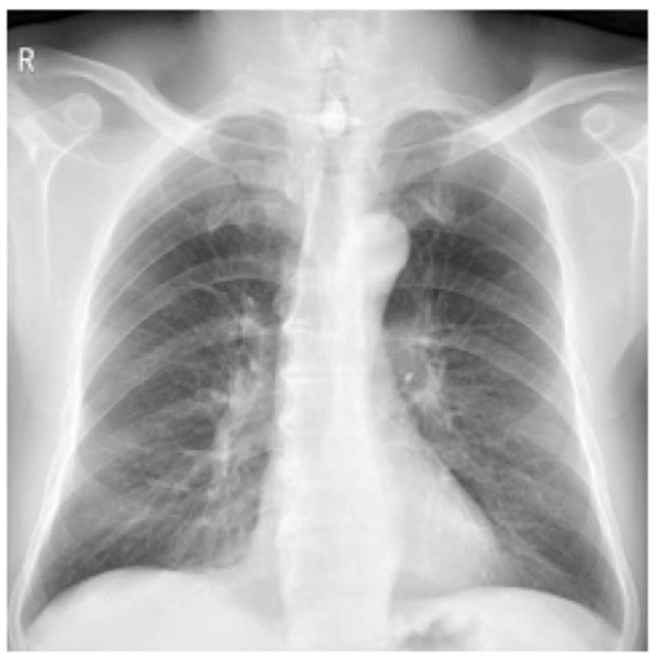

c

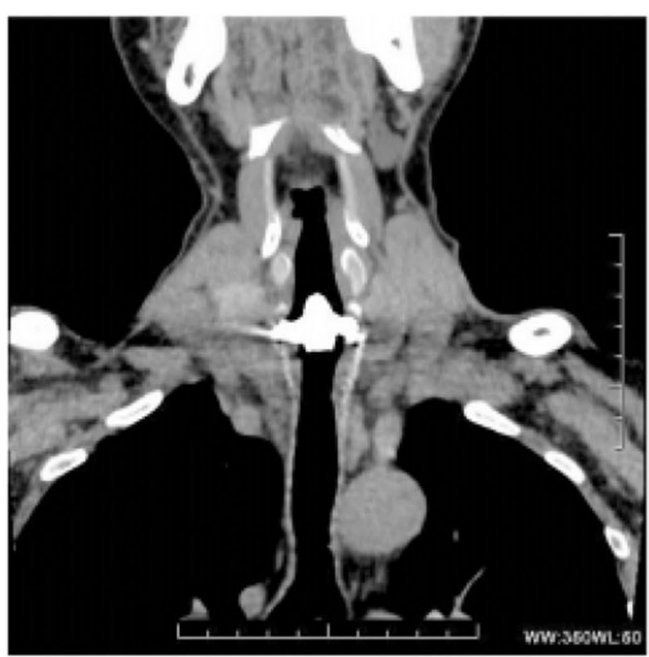

$\mathbf{b}$

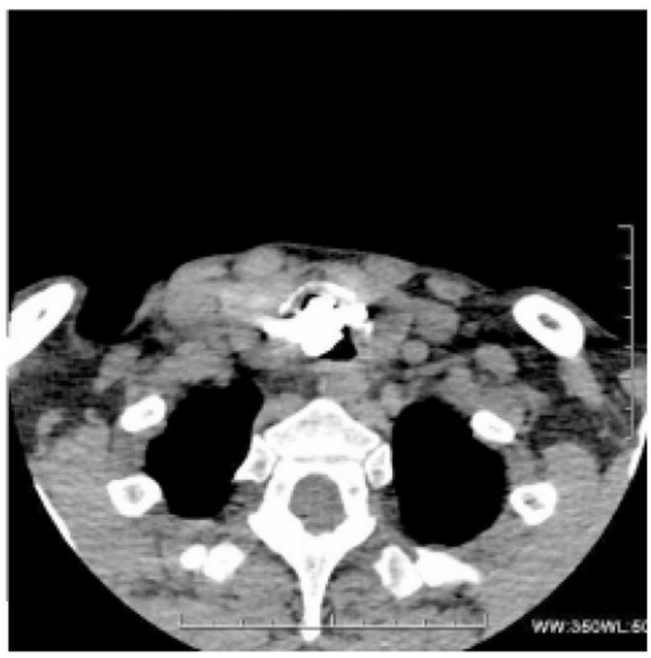

d

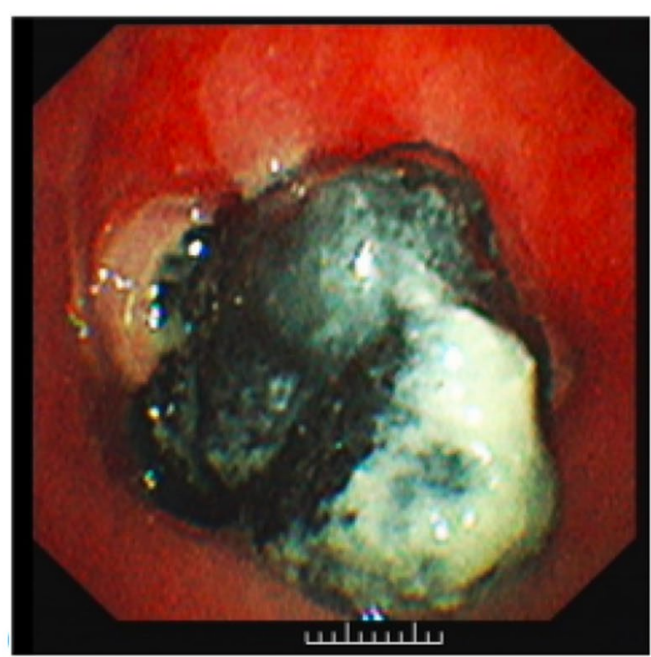

Fig. 1 Radiological examinations and fiberoptic bronchoscopy were performed on a 49-year-old man with a tracheal coal foreign body prior to surgery. a Chest radiograph shows a high-density nodule (arrows) in the trachea about the level of the 7th cervical vertebra. b, c Chest axial and coronal CT images also reveal this high-density nodule (arrows) inserted from the trachea into the right thyroid at the same level as seen on the chest radiograph. $\mathbf{d}$ Fiberoptic bronchoscopy reveals a black foreign body in the subglottic trachea. The tracheal lumen was mostly blocked and the fiberoptic bronchoscopy failed to pass through the trachea due to its severe stenosis

\section{Author details}

1 Department of Radiology, The People's Hospital of Leshan, Leshan

City 614000, People's Republic of China. ${ }^{2}$ Department of Radiology, The Third Affiliated Hospital of Chongqing Medical University (Gener Hospital), 401120, Chongqing, People's Republic of China. ${ }^{3}$ Department of Respiratory, The Third Affiliated Hospital of Chongqing Medical University (Gener Hospital), 401120, Chongqing, People's Republic of China.

Published online: 06 April 2021

\section{Reference}

1. Zhong $L$, et al. An unusual tracheal foreign body in a middle-aged male with a 15-year history of coal use: a case report. BMC Med Imaging. 2021;21:35. https://doi.org/10.1186/s12880-021-00561-z.

\section{Publisher's Note}

Springer Nature remains neutral with regard to jurisdictional claims in published maps and institutional affiliations. 